${ }^{1}$ Physics of Weather and Climate Group, The Abdus Salam International Centre for Theoretical Physics, Trieste, Italy

${ }^{2}$ Department of Geography, University of Connecticut, Storrs, CT, USA

${ }^{3}$ IRI, Columbia University, Palisades, NY, USA

\title{
Domain choice in an experimental nested modeling prediction system for South America
}

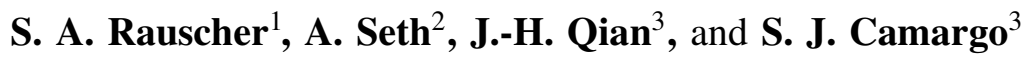 \\ With 9 Figures
}

Received November 15, 2004; revised May 4, 2005; accepted August 22, 2005

Published online June 14, 2006 (C) Springer-Verlag 2006

\begin{abstract}
Summary
The purposes of this paper are to evaluate the new version of the regional model, RegCM3, over South America for two test seasons, and to select a domain for use in an experimental nested prediction system, which incorporates RegCM3 and the European Community-Hamburg (ECHAM) general circulation model (GCM). To evaluate RegCM3, control experiments were completed with RegCM3 driven by both the NCEP/NCAR Reanalysis (NNRP) and ECHAM, using a small control domain (D-CTRL) and integration periods of January-March 1983 (El Niño) and January-March 1985 (La Niña). The new version of the regional model captures the primary circulation and rainfall differences between the two years over tropical and subtropical South America. Both the NNRPdriven and ECHAM-driven RegCM3 improve the simulation of the Atlantic intertropical convergence zone (ITCZ) compared to the GCM. However, there are some simulation errors. Irrespective of the driving fields, weak northeasterlies associated with reduced precipitation are observed over the Amazon. The simulation of the South Atlantic convergence zone is poor due to errors in the boundary condition forcing which appear to be amplified by the regional model.

To select a domain for use in an experimental prediction system, sensitivity tests were performed for three domains, each of which includes important regional features and processes of the climate system. The domain sensitivity experiments were designed to determine how domain size and the location of the GCM boundary forcing affect the regional circulation, moisture transport, and rainfall in two years with different large scale conditions. First, the control domain was
\end{abstract}

extended southward to include the exit region of the Andes low level jet (D-LLJ), then eastward to include the South Atlantic subtropical high (D-ATL), and finally westward to include the subsidence region of the South Pacific subtropical high and to permit the regional model more freedom to respond to the increased resolution of the Andes Mountains (D-PAC). In order to quantify differences between the domain experiments, measures of bias, root mean square error, and the spatial correlation pattern were calculated between the model results and the observed data for the seasonal average fields. The results show the GCM driving fields have remarkable control over the RegCM3 simulations. Although no single domain clearly outperforms the others in both seasons, the control domain, D-CTRL, compares most favorably with observations. Over the ITCZ region, the simulations were improved by including a large portion of the South Atlantic subtropical high (D-ATL). The methodology presented here provides a quantitative basis for evaluating domain choice in future studies.

\section{Introduction}

Regional climate models are increasingly being used for downscaling climate scenarios and for seasonal climate prediction in tropical and subtropical regions where human impact is potentially high and demonstrated skill exists on seasonal timescales. While it is understood that the oneway nested model approach has problems associated with lateral boundary reflection, there has 


\section{S. A. Rauscher et al.}

been relatively little discussion in the literature about these issues and their relationship to domain choice in tropical regions. In this paper, we present a simple sensitivity study of model domain choice for South America, which has been employed in the process of selecting a domain for an experimental climate prediction system and its requisite historical baseline integrations.

For the South American region, a number of studies have begun to evaluate the performance of regional models for their ability to simulate the regional climate in retrospective studies (e.g. Chou et al., 2002; Nicolini et al., 2002; Misra et al., 2002a, b, 2003; Roads et al., 2003) and for use in seasonal climate prediction (e.g. Nobre et al., 2001; Druyan et al., 2002; Qian et al., 2003; Misra and Kanamitsu, 2004; Sun et al., 2005). However, the effect of domain choice on the simulations is not discussed explicitly. In order to investigate its potential for use in seasonal climate prediction, Nobre et al. (2001) employed the National Centers for Environmental Prediction (NCEP) regional spectral model with a domain focused on the tropical Atlantic and Northeast Brazil. The authors noted that their simulations were sensitive to both the model resolution and the location of the lateral boundaries, although they did not provide details. They chose a "compromise" domain that covers most of tropical and subtropical South America and extends eastward into the Atlantic. Misra et al. (2002b) used an even larger domain which includes much of the tropical eastern Pacific and tropical Atlantic Oceans, extending from $30^{\circ} \mathrm{N}$ to $40^{\circ} \mathrm{S}$ and $160^{\circ} \mathrm{W}$ to $10^{\circ} \mathrm{W}$ to compare the effects of different land surface schemes on integrations using the regional spectral model.

Implicit in these studies is that for the regional model to provide more detailed spatial and temporal climate information than the driving GCM, some consideration of domain may be important. For the mid-latitudes, several studies have found that a larger domain reduces the constraints of the lateral boundary conditions, thereby permitting more internal model freedom (Jones et al., 1995; Seth and Giorgi, 1998; Vannitsem and Chomé, 2005). Therefore, the regional model may respond to local topographic and land surface features and processes. As part of larger strategy (Fig. 1, Seth and Rojas, 2003) to test the potential of a regional model (RegCM2) as

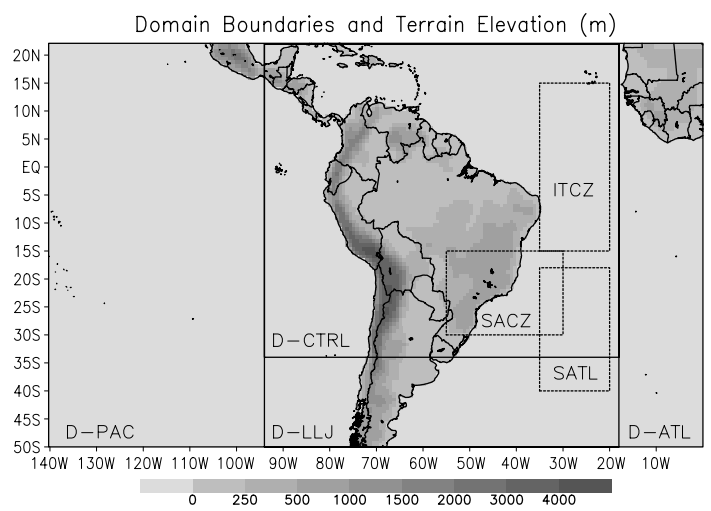

Fig. 1. RegCM3 domains employed: D-CTRL, $143 \times 108$ grid points; D-LLJ, $107 \times 111$ grid points; D-ATL, $131 \times 111$ grid points; D-PAC, $194 \times 111$ grid points (solid). Resolution is $60 \mathrm{~km}$ in D-CTRL and $80 \mathrm{~km}$ in D-LLJ, D-ATL, and D-PAC. Areas used for domain analysis: ITCZ $\left(35^{\circ} \mathrm{W}-20^{\circ} \mathrm{W}: 15^{\circ} \mathrm{S}-15^{\circ} \mathrm{N}\right)$, SACZ $\left(55^{\circ} \mathrm{W}-30^{\circ} \mathrm{W}: 30^{\circ} \mathrm{S}-\right.$ $\left.15^{\circ} \mathrm{S}\right)$, and South Atlantic $\left(35^{\circ} \mathrm{W}-20^{\circ} \mathrm{W}: 40^{\circ} \mathrm{S}-18^{\circ} \mathrm{S}\right)$ (dashed)

part of a nested prediction system over South America, Seth and Rojas (2003) and Rojas and Seth (2003) (hereafter SR03 and RS03) showed that RegCM2 was better able to simulate the location of the ITCZ in a domain which included the Atlantic and Pacific oceans, but not in a smaller domain which constrained the results to the GCM solution. The present study employs a new version of the regional model (RegCM3) and a different GCM (the European CommunityHamburg Model, ECHAM). The testing of this updated experimental nested prediction system offers an opportunity to more formally consider issues related to domain choice. In particular, how might domain choice affect the quality of the output from the nested prediction system?

We therefore have two distinct purposes with this paper: to assess the performance of the new version of RegCM3 over South America, and to select a domain for use in a nested modeling prediction system, which incorporates the updated RegCM3 and the ECHAM GCM. To evaluate RegCM3, control experiments were completed with the regional model driven by both the NCEP/ NCAR Reanalysis (NNRP) and ECHAM, using a control domain (D-CTRL). By discussing the NNRP-driven and ECHAM-driven simulations together, we can more clearly show which errors originate in the regional model and which come from the GCM forcing. To test potential domains for use in the ECHAM-based prediction system, 
a) CMAP Precipitation (mm/day) JFM 1983

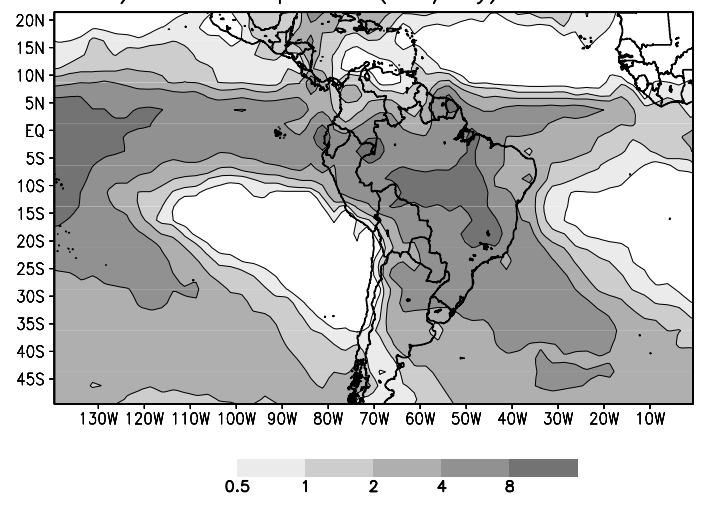

c) CMAP Precipitation ( $\mathrm{mm} /$ day) JFM 1985-1983

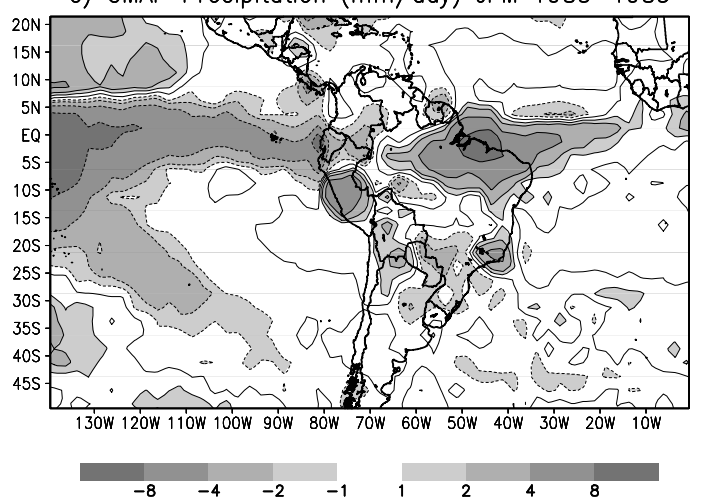

b) ECHAM Precipitation (mm/day) JFM 1983

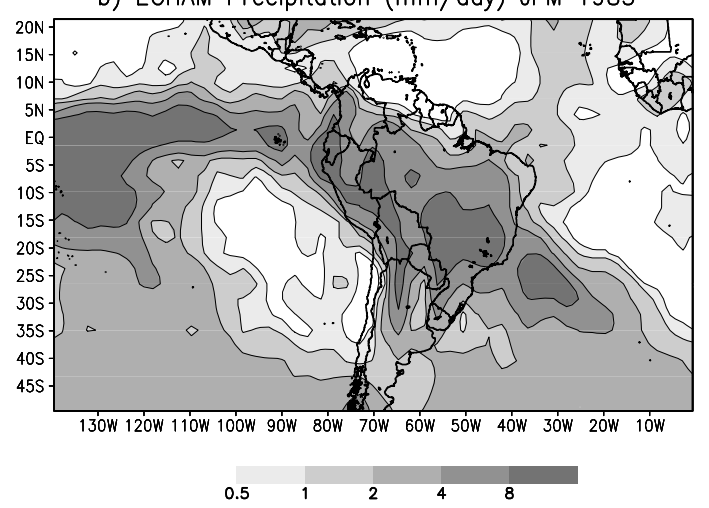

d) ECHAM Precipitation ( $\mathrm{mm} /$ day) JFM 1985-1983

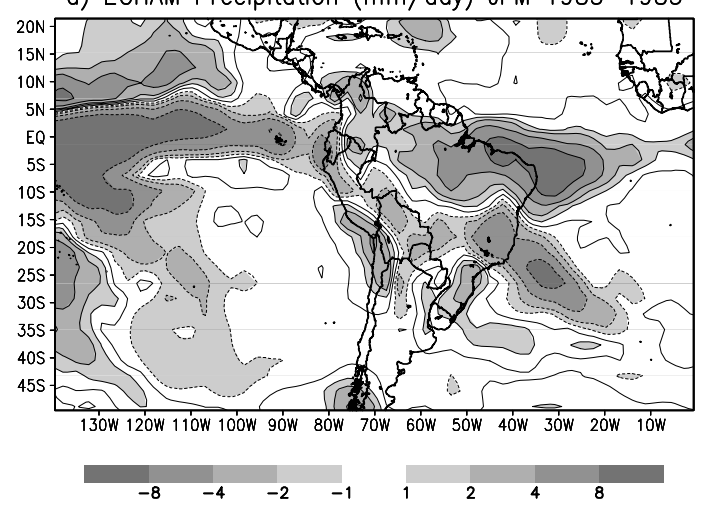

Fig. 2. January-March average precipitation $\left(\mathrm{mm} \mathrm{day}^{-1}\right.$ ) for 1983 for (a) CMAP (b) ECHAM and the difference $1985-1983$ for (c) CMAP and (d) ECHAM. Positive contours are solid, and negative contours are dashed

experiments were performed for the same time period with three sensitivity domains driven by the ECHAM GCM. The domain experiments were analyzed to understand how domain choice affects the simulation of regional features by providing more regional model internal freedom, and by locating domain boundaries where the GCM forcing is more or less skillful.

The experiments were performed for two threemonth periods, JFM 1983 and JFM 1985. Figure 2 of SR03 shows the sea surface temperature (SST) anomalies for the two cases. During the austral summer of 1985, negative SST anomalies were present in the northern equatorial Atlantic while positive SST anomalies were found in the southern equatorial Atlantic, enhancing the meridional SST gradient. The ITCZ moved southward of its climatological position, and large amounts of rain fell over Northeast Brazil. In contrast, the austral summer of 1983 was characterized by positive SST anomalies in the central and eastern equatorial Pacific and in the equatorial North Atlantic. Associated with these positive SST anomalies, the Pacific Walker circulation shifted eastward, resulting in depressed convection and increased subsidence over northern South America and Northeast Brazil. Although the Walker circulation affects the intensity of the ITCZ (Kousky et al., 1984), changes in ITCZ position tend to be related to the meridional SST gradient in the tropical Atlantic (Hastenrath and Heller, 1977; Nobre and Shukla, 1996; Uvo et al., 1998; Chiang et al., 2002). In 1983, with the combination of positive SST anomalies in the Pacific and a weakened tropical Atlantic meridional SST gradient, the ITCZ remained northward of its climatological position, resulting in decreased rainfall over Northeast Brazil. While negative precipitation anomalies prevail over Northeast Brazil and northern South America during a warm ENSO event, positive precipitation anomalies occur over southern Brazil and the subtropical plains of northern Argentina and Uruguay (Ropelewski and Halpert, 1987). These anomalies are associated with an increase in the strength of the South Atlantic subtropical high, 


\section{S. A. Rauscher et al.}

which increases the zonal pressure gradient and enhances moisture transport into subtropical South America through the South American low level jet (Berbery and Barros, 2002).

In Sect. 2, the models and data employed are described. Section 3 presents results from the control domain (D-CTRL) simulations driven by the reanalysis and the GCM, and compares them with observations and the driving fields. Section 4 examines the sensitivity to domain size, with a focus on the simulation of the ITCZ and the South Atlantic convergence zone (SACZ) by the regional model. Section 5 discusses these results and presents conclusions.

\section{Methods}

\subsection{Experiment design}

The parameters for the experiments are listed in Table 1. All experiments were performed for two seasons, JFM 1983 (El Niño) and JFM 1985 (La Niña). Control experiments were completed with RegCM3 driven by both NNRP and ECHAM, using the control domain (D-CTRL). Since our purpose is to evaluate potential domains for use in the ECHAM-based prediction system, the domain sensitivity tests were driven by the ECHAM GCM only. The three sensitivity domains are shown in Fig. 1. Each domain was designed to include specific regional features of the climate system, thereby posing the question: does the GCM adequately represent these features, and can the regional model improve upon the simulation of them?

D-CTRL, the control domain, encompasses most of tropical and subtropical South America, extending from $94^{\circ} \mathrm{W}$ to $18^{\circ} \mathrm{W}$ and $34^{\circ} \mathrm{S}$ to $22^{\circ} \mathrm{N}$ with a horizontal resolution of $60 \mathrm{~km}$. The first sensitivity domain, D-LLJ, has the same longitudinal extent as D-CTRL, but the southern boundary is located at $50^{\circ} \mathrm{S}$ in order to include the exit region of the South American low level jet (LLJ). In the second sensitivity domain, D-ATL, the eastern boundary is extended to the Greenwich Meridian so that South Atlantic subtropical high is represented in the domain. Finally, to permit the regional model more freedom to respond to the increased resolution of the Andes, the western boundary expands westward to $140^{\circ} \mathrm{W}$ in the third sensitivity domain, D-PAC. This largest domain also encompasses part of the South Pacific subtropical high and the eastern and central equatorial Pacific associated with SST anomalies during ENSO events.

In order to render them more computationally efficient for the planned extended integrations (four ensemble members over 1982-2003), the sensitivity domains (D-LLJ, D-ATL, and D-PAC) have a resolution of $80 \mathrm{~km}$. Error statistics calculated for precipitation from D-LLJ run with horizontal resolutions of $60 \mathrm{~km}, 80 \mathrm{~km}$, and $90 \mathrm{~km}$ showed that the difference between the $60 \mathrm{~km}$ and $80 \mathrm{~km}$ simulations was fairly small. While a finer resolution would provide more detailed information about mesoscale features such as the South American LLJ, a resolution of $80 \mathrm{~km}$ nevertheless provides a substantial improvement over the driving fields. This resolution is also being used in several of the modeling experiments that are part of the South American LLJ Experiment (SALLJEX), which is focused on understanding how the South American LLJ affects moisture and energy transport between tropical and subtropical South America (http:// www.usclivar.org/sallj-index.html).

The domain sensitivity experiments were designed to explore how domain size and the location of the GCM boundary forcing affect the regional circulation, moisture transport, and rainfall in two years with different large scale conditions. We chose a single member of a 24member ensemble to drive the simulations. This ECHAM ensemble member was selected based

Table 1. Experiments

\begin{tabular}{lllllll}
\hline Experiment & Driving fields & $d x(\mathrm{~km})$ & Lon $\times$ Lat & Lon & Lat & Features \\
\hline D-CTRL & NNRP/ECHAM & 60 & $143 \times 108$ & $94.0^{\circ} \mathrm{W}-17.4^{\circ} \mathrm{W}$ & $33.5^{\circ} \mathrm{S}-21.6^{\circ} \mathrm{N}$ & Control \\
D-LLJ & ECHAM & 80 & $107 \times 111$ & $93.9^{\circ} \mathrm{W}-17.6^{\circ} \mathrm{W}$ & $49.5^{\circ} \mathrm{S}-21.4^{\circ} \mathrm{N}$ & Continental, LLJ \\
D-ATL & ECHAM & 80 & $131 \times 111$ & $93.9^{\circ} \mathrm{W}-0.4^{\circ} \mathrm{W}$ & $49.5^{\circ} \mathrm{S}-21.4^{\circ} \mathrm{N}$ & ATL STH, ITCZ \\
D-PAC & ECHAM & 80 & $194 \times 111$ & $139.6^{\circ} \mathrm{W}-0.7^{\circ} \mathrm{W}$ & $49.5^{\circ} \mathrm{S}-21.4^{\circ} \mathrm{N}$ & PAC STH \\
\hline
\end{tabular}


on a careful comparison of all 24 ensemble members with observed precipitation and low-level and upper-level winds for the two test cases (JFM 1983 and JFM 1985), and therefore represents the "best-case" driving fields for these two seasons. While an ensemble mean might perform better than this individual ensemble member when evaluated against observations for many years, for these two seasons the individual member is better. The simulations presented here are by necessity short because they were designed to be sensitivity studies to provide a sense for which domain is likely to perform better in the nested prediction system. Although these limited tests cannot deterministically tell us which domain is best, they can provide some guidance. For the next step of this research, we have performed extended simulations with multiple ensemble members, and the results presented in Sect. 4 are consistent with the longer runs.

\subsection{Regional climate model}

The regional model used in these experiments is the third version of the ICTP regional climate model (RegCM3) (Pal et al., 2006). A brief description is provided here with emphasis on the new elements in RegCM3. RegCM3 is a primitive equation, hydrostatic, compressible, sigmacoordinate regional climate model based on NCAR's mesoscale meteorological model, MM4 (Anthes et al., 1987). The model's vertical resolution is 18 levels with 7 levels below $800 \mathrm{hPa}$. The radiation parameterization used is the CCM3 radiation package of Kiehl et al. (1996). Exchanges of energy, moisture, and momentum between the land surface and the atmosphere are computed using the BATS1E land surface model (Dickinson et al., 1993). RegCM3 uses a medium-resolution planetary boundary scheme developed by Holtslag et al. (1990). Convective precipitation is represented using the Grell cumulus parameterization scheme (Grell, 1993) with the Arakawa-Schubert closure (Arakawa and Schubert, 1974). In the Grell scheme, clouds consist of an updraft and a downdraft, with no direct mixing between the two except at the top and bottom of the circulations.

New features in RegCM3 include the surface flux scheme over the oceans and a subgrid explicit moisture scheme. The surface flux scheme of Zeng et al. (1998) corrects the tendency of
BATS1E to overestimate latent heat flux over the oceans in both weak and strong wind conditions (J. Pal, personal communication, 2004), and in general results in decreased precipitation over the oceans. Resolvable precipitation processes are treated with the subgrid explicit moisture scheme (SUBEX) of Pal et al. (2000). SUBEX is a physically based parameterization that includes variation at the subgrid scale of clouds, cloudwater accretion, and evaporation of raindrops.

\subsection{Global climate model (ECHAM)}

The European Community-Hamburg (ECHAM, version 4.5) is an atmospheric general circulation model derived from the European Centre for Medium-Range Weather Forecasts (ECMWF) spectral prediction model (Simmons et al., 1989) by Roeckner et al. (1996). It has a hybrid sigmapressure vertical coordinate. In the ensemble member used in these experiments, ECHAM has a horizontal T42 spectral resolution $\left(2.8^{\circ}\right.$ latitude-longitude) and has 19 vertical levels, with the top extending to $10 \mathrm{hPa}$. The model's prognostic variables are vorticity, divergence, surface pressure, temperature, specific humidity, and the mixing ratio of total cloud water. The mass flux scheme of Tiedtke (1989) is employed for both deep and shallow convection. Radiative fluxes in the model follow a modified version of the ECMWF formulation of Fouquart and Bonnel (1980) and Morcrette et al. (1986). For full details on the ECHAM model, readers may refer to Roeckner et al. (1996).

\subsection{Data}

Model initial and lateral boundary conditions were created using one "best" ensemble member of ECHAM (described in the preceding section), which was chosen based upon a comparison with observed precipitation and low level and upper level winds for the 1983 and 1985 austral summer seasons, and the NCEP/NCAR Reanalysis (NNRP) (Kalnay et al., 1996). NNRP is derived from various data sources including rawinsondes, surface marine data, aircraft data, surface land synoptic data, satellite sounder data, special sensing microwave imager, and satellite cloud drift winds. Quality control studies are performed and the data is assimilated using a numerical pre- 


\section{S. A. Rauscher et al.}

diction model. SSTs were obtained from the NOAA optimum interpolation (OI) SST analysis (Version 2) of Reynolds et al. (2002). The modeloutput precipitation is compared with the Climate Prediction Center Merged Analysis of Precipitation (CMAP) (Xie and Arkin, 1996). CMAP is a blended product of global satellite and gauge data on a $2.5^{\circ}$ latitude-longitude grid available as pentads and monthly averages.

\section{Results: control simulations}

Here results are presented from the control simulations of RegCM3 driven by NNRP and the ECHAM GCM for the 1983 and 1985 JFM seasons. By discussing the NNRP-driven and ECHAM-driven simulations together, we can more clearly show which errors originate in the regional model and which come from the GCM forcing. Unless otherwise stated, all discussion of the ECHAM GCM refers to the performance of the single ensemble member chosen to drive the simulations, which is our "best case" scenario to evaluate how the nested modeling system might perform.

\subsection{Precipitation}

Figure 2 shows the JFM 1983 and JFM 1985-1983 precipitation in $\mathrm{mm} \mathrm{day}^{-1}$ for the CMAP observations (a, c) and the ECHAM GCM (b, d). In 1983, the CMAP data show a well developed ITCZ located near $5^{\circ} \mathrm{N}$, relatively dry conditions over Northeast Brazil, and larger rainfall amounts over the southern Amazon, southeast Brazil, and the SACZ. Overall, the ECHAM GCM replicates the observed pattern of precipitation fairly well, especially over the continent. However, in the ECHAM GCM the ITCZ is a weak, amorphous rainfall region which extends into the subtropical North Atlantic. Over southeastern Brazil, the area of maximum precipitation associated with the SACZ is located southward of its observed position. In addition, the GCM precipitation rates are higher than are the observed precipitation estimates in a corridor located to the east of the Andes mountains that extends from western Brazil to northern Argentina.

The difference maps for 1985-1983 illustrate the dramatic increase and slight southward shift in ITCZ rainfall in 1985 as compared to 1983.
This increase is captured by the GCM, but as the simulated ITCZ was weak in 1983, no shift is seen. The CMAP data show the differences between the two test cases are not as pronounced over southern Brazil, Paraguay, and northern Argentina compared to Northeast Brazil. Nonetheless, precipitation was reduced in this region in 1985, consistent with the decreased (increased) precipitation often observed during a(n) La Niña (El Niño) (Ropelewski and Halpert, 1987). In the observed data, the SACZ extends southward in 1983 relative to 1985 , which is in agreement with the tendency for the SACZ to move southward and strengthen during warm ENSO events when convection is enhanced in the central Pacific (Nogués-Paegle and Mo, 1997). However, in the ECHAM GCM the SACZ appears to be in its southern position in 1985, as the 1985-1983 differences show dry conditions in southeastern Brazil and wet conditions in southern Brazil, Uruguay, and parts of northern Argentina. Given that this realization is the best of 24 ensemble members, it appears that the ECHAM GCM is demonstrating a problem in the region of the SACZ.

As shown in Fig. 3, in 1983 both the NNRPdriven RegCM3 (a) and ECHAM-driven (b) capture the observed spatial distribution of precipitation over the domain with several notable differences. First, the ECHAM-driven RegCM3 greatly improves upon the simulation of the Atlantic ITCZ as compared to the global model, but its location still appears to be south of the observed in the ECHAM-driven simulation. The NNRP-driven RegCM3 places the ITCZ farther north than does the ECHAM-driven RegCM3. Second, precipitation is underestimated over the Amazon Basin by both the ECHAM-driven and NNRP-driven RegCM3. This same deficiency in precipitation was observed by $\mathrm{RS} 03$ and SR03 using $\operatorname{RegCM} 2$, and was linked to a weakening of the northeasterlies and associated low-level moisture transport. Third, the SACZ is not very well formed in either the ECHAM-driven and NNRP-driven simulations. Precipitation is overestimated over southern Bolivia, Paraguay, and northern Argentina, where both models show a large area with a precipitation rate in excess of $8 \mathrm{~mm} \mathrm{day}^{-1}$, twice that of the observed precipitation rate in that region. Finally, the maps of the 1985-1983 precipitation (Fig. 3) show that both 

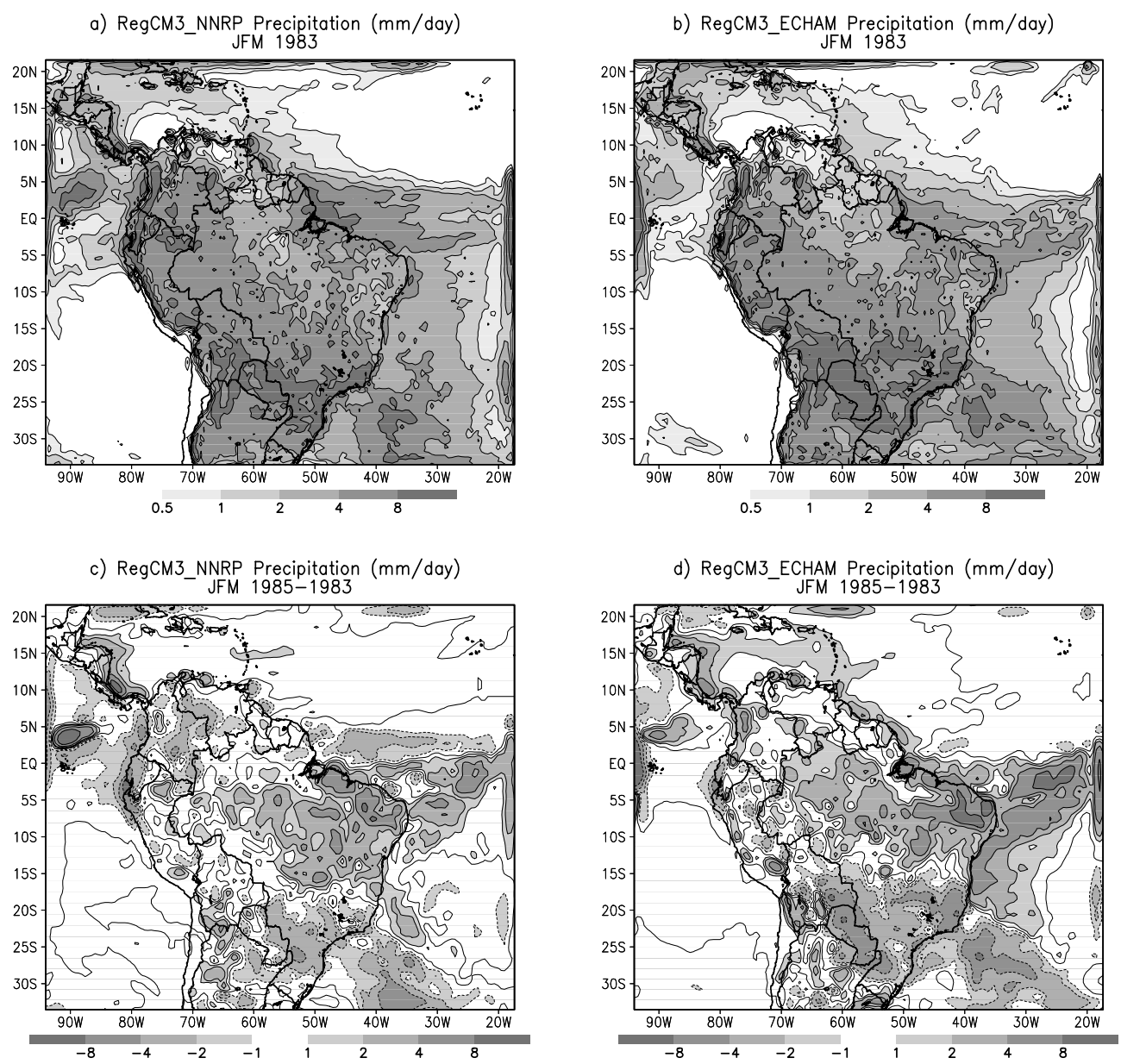

Fig. 3. January-March average precipitation $\left(\mathrm{mm} \mathrm{day}^{-1}\right)$ for 1983 for (a) NNRP-driven RegCM3 (b) ECHAM-driven RegCM3 and for the difference 1985-1983 (smoothed) for (c) NNRP-driven RegCM3 and (d) ECHAM-driven RegCM3. Positive contours are solid, and negative contours are dashed

the ECHAM-driven RegCM3 (d) and the NNRPdriven RegCM3 (c) are able to reproduce the differences between the two years. The NNRPdriven simulations capture the southward shift in the ITCZ in 1985. Over southeastern and south-central Brazil, both models show negative anomalies consistent with the observations. It is noteworthy that the ECHAM-driven RegCM3 locates these negative anomalies farther southward than the GCM, resulting in an anomaly field that is closer to the observed in this region.

\subsection{Circulation}

Simulated and observed low level wind differences between the two years yield some insights into the precipitation results shown above. The 1985-1983 $850 \mathrm{hPa}$ winds for the NNRP (a) and ECHAM GCM (b) are shown in Fig. 4. Regions of divergence (convergence) are shaded with light (dark) gray. Over the North Atlantic and the ITCZ region, the GCM and the reanalysis show some similarities. The northeasterlies entering the South American continent were stronger in 1985 than in 1983, consistent with the negative SST anomalies in the equatorial North Atlantic, as stronger than normal trades are associated with negative local SST anomalies, and vice versa (Nobre and Shukla, 1996; Enfield and Mayer, 1997). The increased convergence over Northeast Brazil is also readily apparent.

However, over the South Atlantic and subtropical South America, the circulation anomalies differ between the reanalysis and the GCM. While NNRP shows a cyclonic anomaly over southeastern Brazil, the ECHAM GCM shows an anticyclonic anomaly in the region of the SACZ. To investigate further, Fig. 5 shows the seasonal 

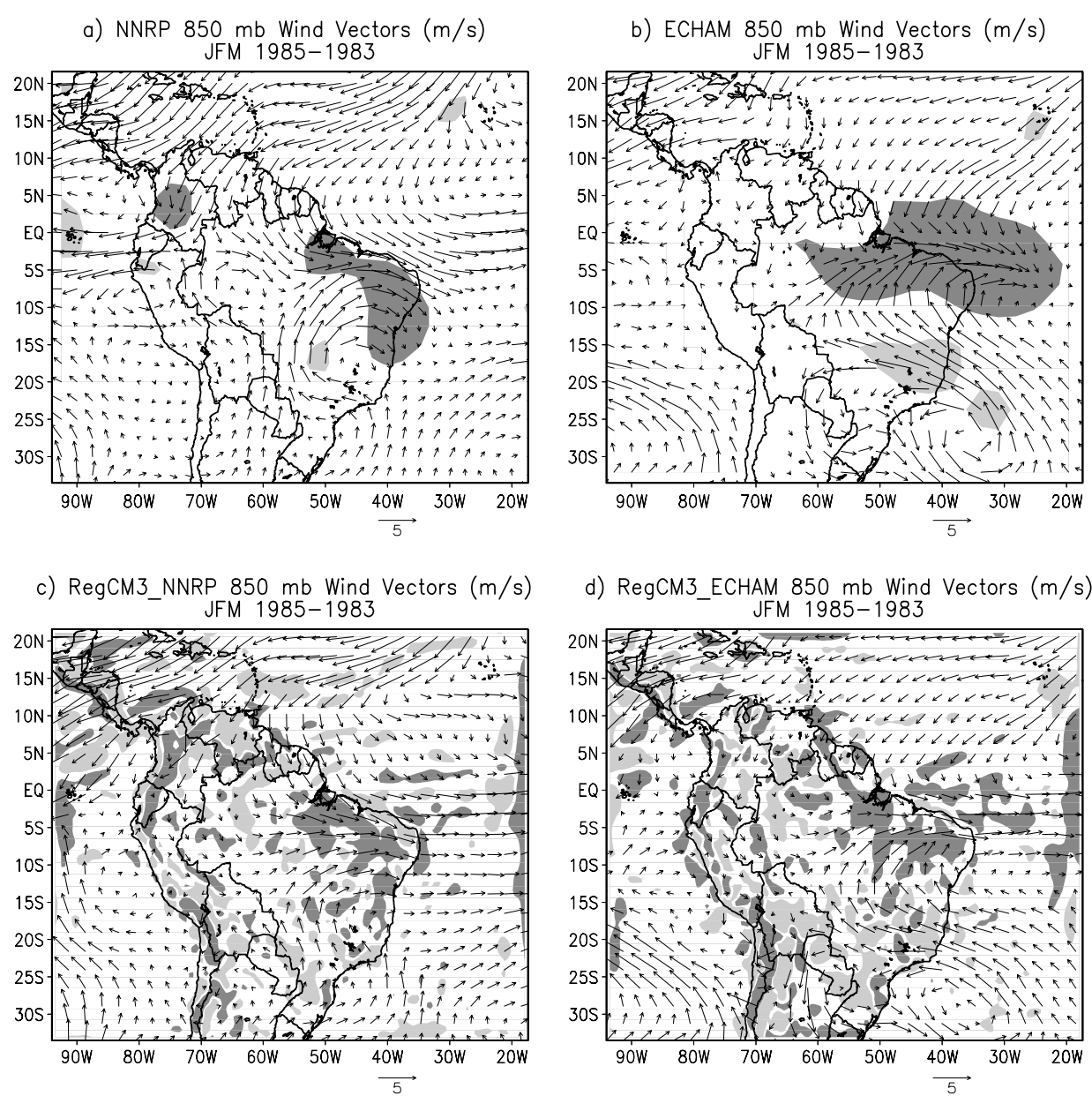

Fig. 4. January-March difference $1985-1983850 \mathrm{hPa}$ Wind Vectors $\left(\mathrm{m} \mathrm{s}^{-1}\right)$ and divergence ( $\mathrm{s}^{-1}$, shading) from (a) NNRP (b) ECHAM GCM (c) NNRP-driven RegCM3 and (d) ECHAM-driven RegCM3 (right). Divergence values greater than $1.5 * 10 \mathrm{e} 5$ and less than $-1.5 * 10 \mathrm{e} 5$ are shaded

mean (JFM) sea level pressure in hPa for NNRP and ECHAM for 1985 and 1983. Typically during warm ENSO events, the South Atlantic subtropical high strengthens. This relationship can be clearly seen in the plots of NNRP sea level pressure (SLP), which indicate that the South Atlantic subtropical high was stronger in 1983 (a) than in 1985 (c). However, in the ECHAM simulation, this relationship is reversed with 1985 (b) displaying a stronger South Atlantic subtropical high than the 1983 (d) case. In addition, in both the 1985 and 1983 ECHAM simulations the South Atlantic subtropical high is stronger and displaced southward relative to NNRP. This positive bias in the SLP field is also found in the ECHAM ensemble mean (not shown), and has been documented by the model developers (Roeckner et al., 1996), who noted that the stronger and more poleward shifted subtropical anticyclones in the southern hemisphere indicate over-emphasized Walker circulations in the equatorial region.

These differences in the location and intensity of the subtropical high in the GCM relative to the NNRP have consequences for moisture transport into subtropical South America. There are two main pathways of moisture transport from tropical South America to subtropical South America: a northerly LLJ with average wind speeds of $15 \mathrm{~m} \mathrm{~s}^{-1}$ located just east of the Andes at $10^{\circ} \mathrm{S}$, $65^{\circ} \mathrm{W}$ (Virji, 1981; Paegle, 1998) and northerly flow out of the SACZ that occurs to the east of the South American LLJ (Seluchi and Marengo, 2000; Herdies et al., 2002). Both of these avenues of moisture transport are connected to the strength and position of the South Atlantic subtropical high and the Chaco Low, a thermal low located near $22^{\circ} \mathrm{S}$ and $60^{\circ} \mathrm{W}$ (Schwerdtfeger, 1976). In austral spring and summer, the Chaco 
a) NNRP Sea Level Pressure (hPa) JFM 1983

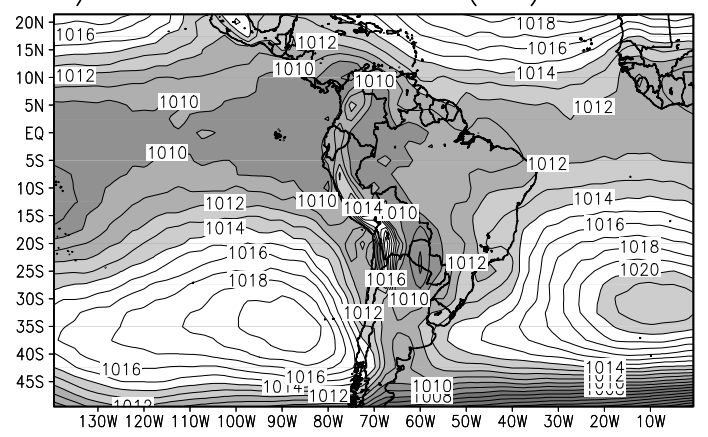

c) NNRP Sea Level Pressure (hPa) JFM 1985

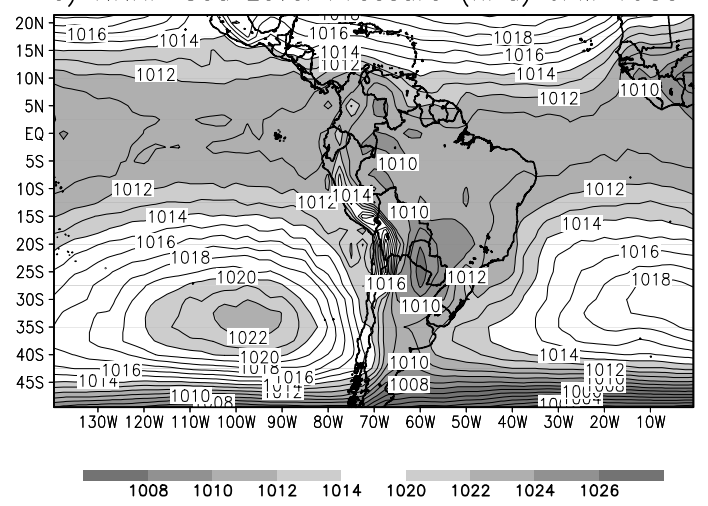

b) ECHAM Sea Level Pressure (hPa) JFM 1983

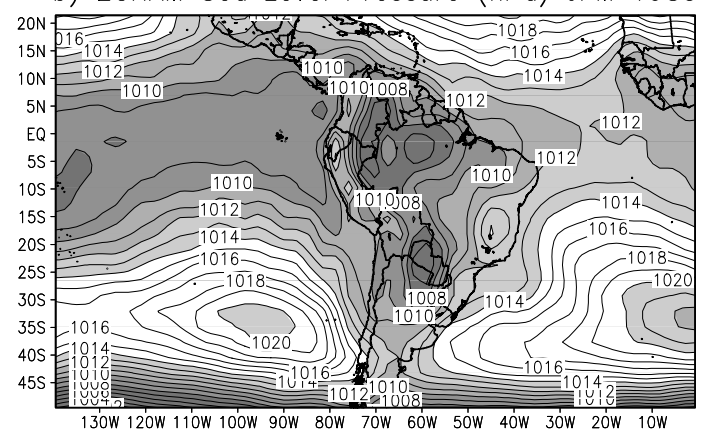

d) ECHAM Sea Level Pressure (hPa) JFM 1985

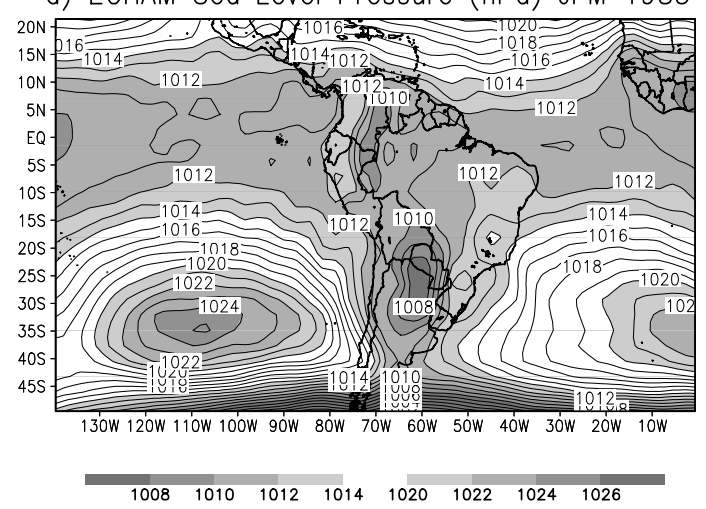

Fig. 5. January-March average sea level pressure (hPa) for 1983 for (a) NNRP and (b) ECHAM GCM and for 1985 for (c) NNRP and (d) ECHAM GCM. Values greater than $1020 \mathrm{hPa}$ and less than $1014 \mathrm{hPa}$ are shaded

low intensifies due to strong heating from high radiation receipts and low moisture at the surface. The pressure gradient between the Chaco Low and the South Atlantic subtropical high sets up northeasterly flow that transports moisture into the continent (Paegle and Mo, 2002). During warm ENSO events, the South Atlantic subtropical high is strengthened, enhancing this moisture transport into subtropical South America. Associated positive precipitation anomalies occur over southern Brazil and the subtropical plains (Ropelewski and Halpert, 1987; Paegle and Mo, 2002). In addition, there is some evidence linking a stronger South American LLJ to warm ENSO events (Berbery and Barros, 2002). These patterns are evident in the reanalysis, where we see that the northerly winds are stronger in the jet region in 1983 than in 1985, consistent with the presence of a stronger South Atlantic subtropical high. However, the strengthening of the South American LLJ is not as clear in the ECHAM GCM, as the 1985-1983 difference plots (Fig. 4) show northerly anomalies south of $15^{\circ} \mathrm{S}$ and southerly anomalies north of $15^{\circ} \mathrm{S}$ in the jet region.
To a large extent, the circulation patterns of the ECHAM-driven (Fig. 4d) and NNRP-driven RegCM3 (Fig. 4c) follow the driving fields. In each nested model, the northeasterlies entering the South American continent are clearly stronger in 1985 than in 1983, and convergence is enhanced over Northeast Brazil. However, there are differences over subtropical South America. Both the ECHAM-driven and NNRP-driven RegCM3 show stronger northerly and northwesterly flow east of the Andes Mountains (i.e. an enhancement of the LLJ) over Bolivia, Paraguay, and northern Argentina as compared to the driving fields in both 1983 and 1985 (not shown). In addition, in both cases the wind speed maximum is located farther south in the ECHAM-driven regional model. This is a result of the anomalous anticyclone in the SACZ, and it is consistent with the southward displacement of the subtropical highs in the ECHAM GCM. Consequently, moisture transport is increased relative to the reanalysis and GCM from tropical to subtropical South America, which is likely related to the presence of excessive pre- 
cipitation in the exit region of the LLJ in 1985 and 1983.

\section{Domain sensitivity}

The control simulations showed that while both the GCM and the regional model capture the main precipitation and circulation features of the two extreme cases, there are some simulation errors. Over the ITCZ region, the regional model appears to improve upon the GCM. While the
NNRP-driven simulations place the ITCZ position closer to observations, the ECHAM-driven simulations show a great improvement of the overall simulation of the ITCZ compared to the GCM. The weak northeasterlies and reduced precipitation over the Amazon are consistent between the NNRP-driven RegCM3 and the ECHAMdriven RegCM3, indicating a regional model bias. The location and intensity of the SACZ are affected by problems in the simulation of the South Atlantic subtropical high. This problem a) D-LLJ Precipitation (mm/day) JFM 1983

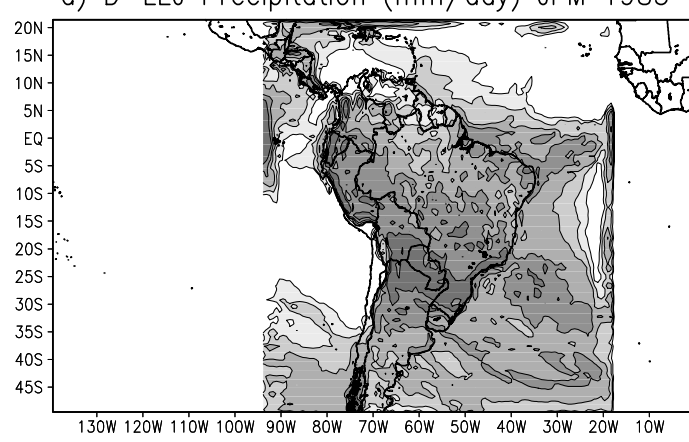

b) D-ATL Precipitation ( $\mathrm{mm} /$ day) JFM 1983

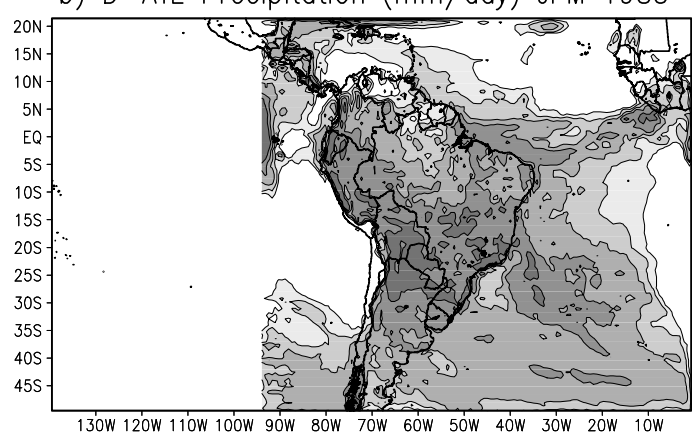

c) D-PAC Precipitation ( $\mathrm{mm} /$ day) JFM 1983

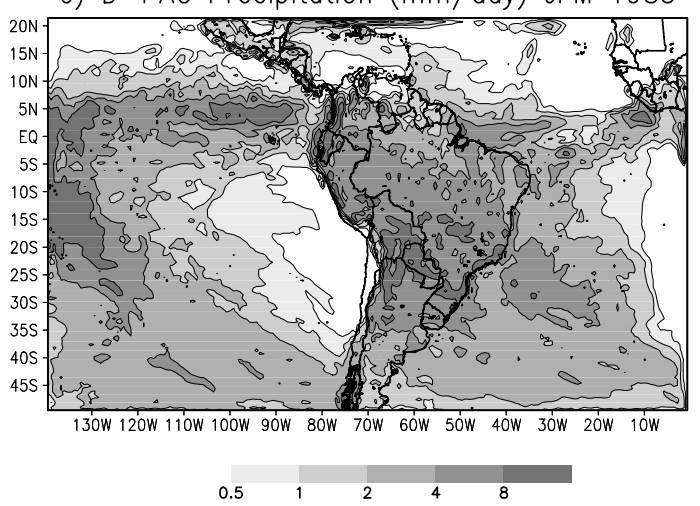

d) D-LLJ Precipitation (mm/day) JFM 1985-1983

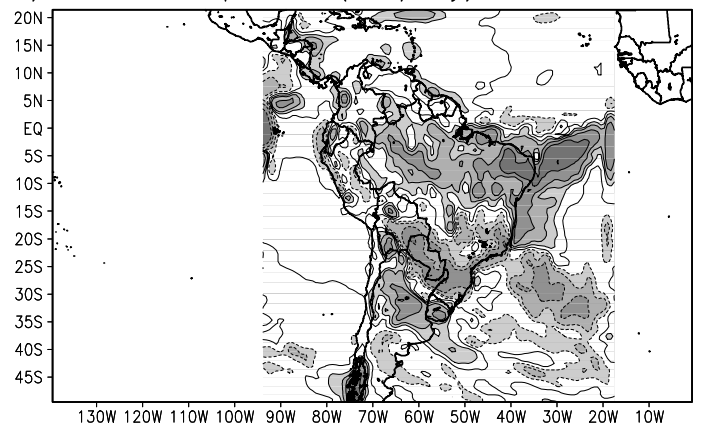

e) D-ATL Precipitation (mm/day) JFM 1985-1983

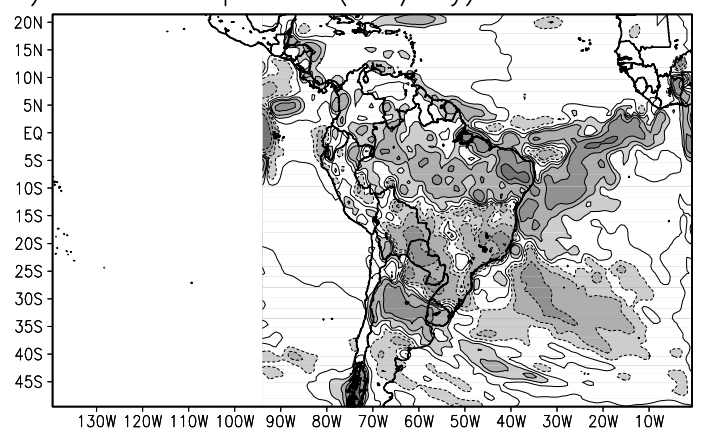

f) D-PAC Precipitation (mm/day) JFM 1985-1983

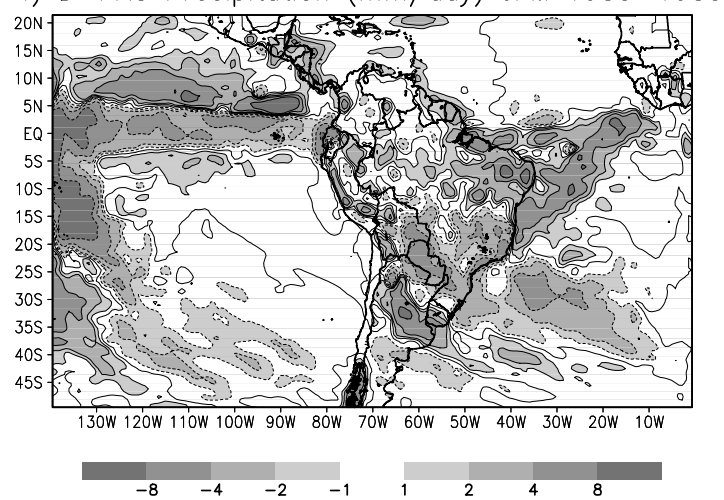

Fig. 6. January-March precipitation $\left(\mathrm{mm} \mathrm{day}^{-1}\right.$ ) for the ECHAM-driven RegCM3 for 1983 for (a) D-LLJ, (b) D-ATL, and (c) D-PAC and for 1985-1983 (smoothed) for (d) D-LLJ, (e) D-ATL, and (f) D-PAC. Positive contours are solid, and negative contours are dashed 
appears to be worse in the ECHAM-driven RegCM3 because of the positive bias in sea level pressure observed in the ECHAM GCM. Because we have seen that domain can potentially improve some aspects of the simulation (e.g. RS03), we explore next if and how the results are modified by choice of domain.

In the sensitivity results, the three domain experiments are discussed in terms of their performance over three regions represented by their key circulation feature: ITCZ, SACZ, and the South Atlantic subtropical high. These regions are shown in Fig. 1. In order to quantify differences between the domain experiments, measures of bias, root mean square error, and the spatial correlation pattern were calculated between the model results and the observed data for the seasonal average fields. The CMAP precipitation data and NNRP sea level pressure data were used as the observed fields in the calculation of the error statistics. For all of the performance measures, the observations were interpolated on to the regional and global model grids for the regional model results and global model results, respectively. The grid used for interpolation did not change how the domains performed relative to each other. The statistics were computed only for the domains that contained the entire region of interest.

\subsection{ITCZ}

The regional model improves upon the simulation of the ITCZ compared to the driving GCM, both in location and spatial extent. Figure 6 shows the seasonal mean (JFM) precipitation in $\mathrm{mm} \mathrm{day}^{-1}$ for the sensitivity domains (D-LLJ, DATL, and D-PAC) for 1983 (a-c) and 1985-1983 (d-f). The CMAP, ECHAM GCM, and D-CTRL precipitation fields are shown in Figs. 2 and 3. The regional model clearly simulates an ITCZ that is more similar to the observations than the GCM. In addition, the two largest domains (D-ATL and D-PAC) appear to place the ITCZ farther northward than the smaller domains, which again compares more favorably with the CMAP data.

To quantify this improvement, the ITCZ position was calculated for each regional model simulation, the ECHAM GCM, and the CMAP observations. All of the data were interpolated to the grid of the largest regional domain, D-PAC. We defined the ITCZ position by determining the latitude of the maximum precipitation from $15^{\circ} \mathrm{S}$ to $15^{\circ} \mathrm{N}$ at each grid point longitude. If the maximum precipitation is less than $2 \mathrm{~mm} \mathrm{day}^{-1}$, then the ITCZ position is undefined for that longitude. This additional criterion was added because of the poor simulation of the ITCZ by the ECHAM GCM in 1983, when the presence of some precipitation maxima in the far northern part of the defined ITCZ region yielded ITCZ positions north of $10^{\circ} \mathrm{N}$.

Figure 7 shows the average JFM 1985 ITCZ. The CMAP data indicate that the ITCZ is located near the equator at most longitudes. There is a slight northward trend from west to east across

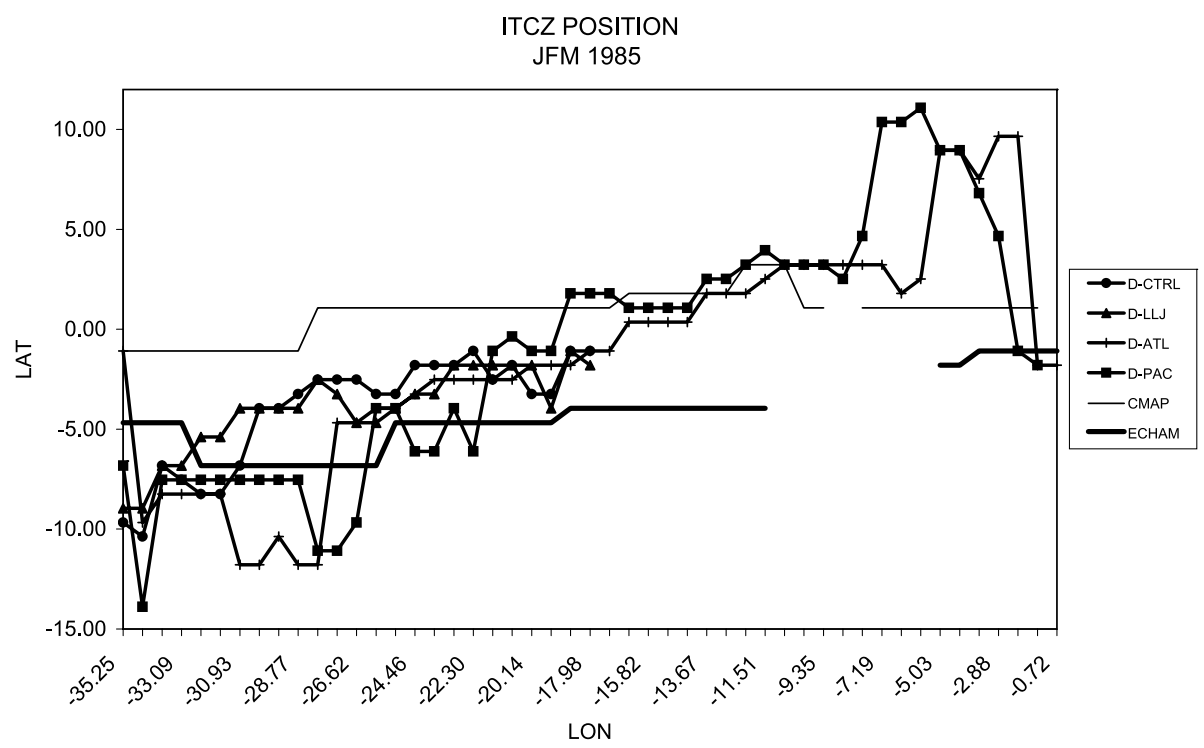

Fig. 7. ITCZ Position for January-March 1985 from observations, the ECHAM GCM, and the RegCM3 domains 


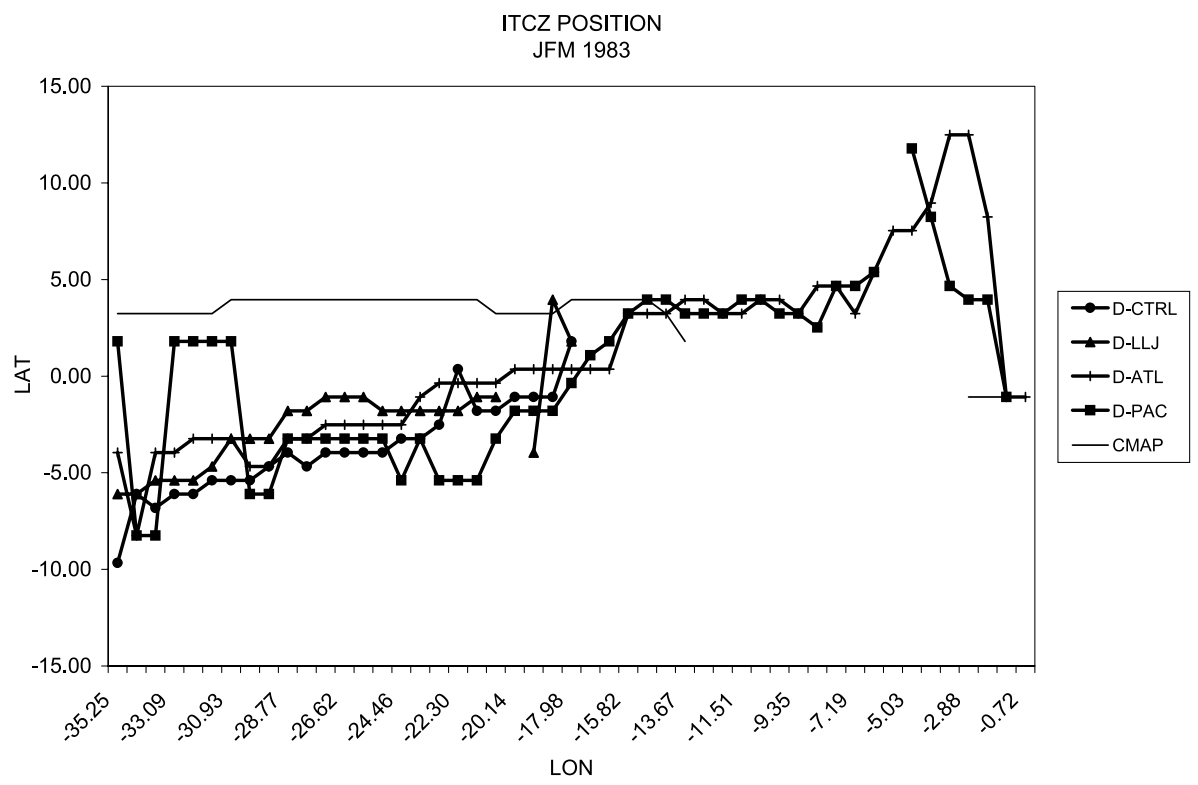

Fig. 8. ITCZ Position for January-March 1983 from observations, the ECHAM GCM, and the RegCM3 domains the Atlantic. The ECHAM GCM places the ITCZ approximately $5^{\circ} \mathrm{S}$ of its observed location, but the northward trend seen in the observed data is reproduced. In D-ATL and D-PAC, the ITCZ is located south of the ECHAM GCM position from $35^{\circ} \mathrm{W}$ to approximately $25^{\circ} \mathrm{W}$. With the exception of D-PAC, the ITCZ is closer to its observed position eastward of $25^{\circ} \mathrm{W}$ in all of the domains. It is interesting to note that the larger domains perform better in the central equatorial Atlantic and less well near the coast of South America.

The northward shift of the ITCZ in 1983 relative to 1985 is clearly seen in the CMAP data in Fig. 8. The ITCZ is located approximately at $4^{\circ} \mathrm{N}$, several degrees northward of its 1985 position. As described in Sect. 2, the ECHAM GCM poorly simulates the intensity and position of the ITCZ in 1983. Because of the criterion for a minimum of $2 \mathrm{~mm} \mathrm{day}^{-1}$, the ITCZ is undefined at all longitudes in the ECHAM GCM simulation. The regional model domains all simulate an ITCZ but place it southward of its observed location, although the northward shift of the ITCZ (approximately $5^{\circ}$ northward) in 1983 compared to 1985 is clearly shown. However, the regional model domains have a pronounced northward trend from west to east that is not as dramatic in the CMAP data.

The analysis of the ITCZ positions shows that the regional model was able to improve upon the simulation of the intensity and position of the ITCZ. Table 2 lists the spatial pattern correlation, bias, and RMS error statistics for precipitation in the oceanic ITCZ region, defined as $35^{\circ}-$ $20^{\circ} \mathrm{W}: 15^{\circ} \mathrm{S}-15^{\circ} \mathrm{N}$. The eastern boundary for this region was extended only to $20^{\circ} \mathrm{W}$ to be consistent between all of the domains. In both years, all of the regional model domains have smaller biases than does the GCM. As would be expected from the discussion of the ITCZ position, for the 1983 case the spatial pattern correlations for the regional model domains are much higher than the GCM. In 1985, the spatial pattern

Table 2. Spatial pattern correlation (SCOR), bias (BIAS), and root mean square error (RMSE) for precipitation (PPT) $\left(\mathrm{mm} \mathrm{day}^{-1}\right)$ for January-March 1983 and 1985 over the ITCZ region, $35^{\circ}-20^{\circ} \mathrm{W}: 15^{\circ} \mathrm{S}-15^{\circ} \mathrm{N}$

\begin{tabular}{|c|c|c|c|c|c|c|c|c|c|c|}
\hline \multirow{2}{*}{$\begin{array}{l}\text { PPT } \\
\text { STAT }\end{array}$} & \multicolumn{5}{|l|}{1983} & \multicolumn{5}{|l|}{1985} \\
\hline & GCM & D-CTRL & D-LLJ & D-ATL & D-PAC & GCM & D-CTRL & D-LLJ & D-ATL & D-PAC \\
\hline SCOR & 0.29 & 0.45 & 0.47 & 0.47 & 0.40 & 0.43 & 0.52 & 0.43 & 0.33 & 0.31 \\
\hline BIAS & -0.68 & 0.09 & -0.06 & -0.12 & -0.03 & 1.63 & 1.00 & 1.08 & 0.69 & 0.94 \\
\hline RMSE & 1.55 & 1.76 & 1.74 & 1.51 & 1.61 & 4.81 & 3.70 & 4.84 & 3.28 & 3.62 \\
\hline
\end{tabular}


Table 3. Spatial pattern correlation (SCOR), bias (BIAS), and root mean square error (RMSE) for precipitation (PPT) (mm $\mathrm{day}^{-1}$ ) and sea level pressure (SLP) (hPa) for January-March 1983 and 1985 over the SACZ region: $55^{\circ}-30^{\circ} \mathrm{W}^{\circ} 30^{\circ}-15^{\circ} \mathrm{S}$

\begin{tabular}{|c|c|c|c|c|c|c|c|c|c|c|}
\hline \multirow[t]{2}{*}{ STAT } & \multicolumn{5}{|l|}{1983} & \multicolumn{5}{|l|}{1985} \\
\hline & GCM & D-CTRL & D-LLJ & D-ATL & D-PAC & GCM & D-CTRL & D-LLJ & D-ATL & D-PAC \\
\hline \multicolumn{11}{|l|}{ PPT } \\
\hline SCORR & 0.74 & 0.51 & 0.37 & 0.46 & 0.44 & 0.21 & -0.02 & -0.06 & -0.07 & -0.1 \\
\hline BIAS & 1.04 & 0.40 & -0.38 & -0.37 & -0.37 & -1.63 & -1.40 & -1.59 & -1.63 & -1.9 \\
\hline RMSE & 2.25 & 2.76 & 3.14 & 2.66 & 2.46 & 3.53 & 3.57 & 3.66 & 3.68 & 3.95 \\
\hline \multicolumn{11}{|l|}{ SLP } \\
\hline SCORR & 0.91 & 0.97 & 0.95 & 0.92 & 0.94 & 0.92 & 0.95 & 0.93 & 0.90 & 0.88 \\
\hline BIAS & -0.54 & 0.64 & 1.12 & 1.19 & 1.37 & 2.09 & 3.10 & 3.82 & 4.02 & 3.92 \\
\hline RMSE & 0.96 & 0.81 & 1.31 & 1.44 & 1.50 & 2.19 & 3.17 & 3.95 & 4.19 & 4.16 \\
\hline
\end{tabular}

correlations for the regional model are similar to the GCM. While the regional model appears to perform better than the GCM over the ITCZ region, no single regional model domain clearly outperforms the others. In 1983, D-ATL has arguably the best performance overall when considering all three error statistics. However, the control domain (D-CTRL) appears to perform slightly better than the other domains in 1985 .

The error statistics show that expanding the domain to the Atlantic (D-ATL) enhanced model performance over the ITCZ region in 1983. However, D-PAC did not provide any additional improvement. This suggests that the relationship between the climate variables over the eastern Pacific and our regions of interest operate at a sufficiently large scale so that the regional model cannot provide improvement over the forcing GCM. The regional model did not meliorate the simulation of the South Pacific subtropical high, and the large positive bias in SLP in the regional model seen over the South Atlantic was also observed for the South Pacific. In addition, the simulation of precipitation over the South Pacific deteriorates relative to the GCM. In D-PAC, the increased internal model freedom does not appear to provide added value to the simulation.

\subsection{SACZ and the South Atlantic}

Figure 6 shows the seasonal mean (JFM) precipitation in $\mathrm{mm} \mathrm{day}^{-1}$ for the sensitivity domains (D-LLJ, D-ATL, and D-PAC) for 1983 (a-c) and 1985-1983 (d-f). The CMAP, ECHAM GCM, and D-CTRL precipitation fields are shown in Figs. 2 and 3. As described in Sect. 2, neither the ECHAM GCM nor the RegCM3 control simulations simulate the SACZ very well. In 1985 (not shown), none of the domains reproduce the observed precipitation of $8 \mathrm{~mm}$ day $^{-1}$ or more near the southeast coast of Brazil around $25^{\circ} \mathrm{S}$, $40^{\circ}-45^{\circ} \mathrm{W}$. Instead, there are precipitation maxima located along the Brazilian coast north of the observed SACZ location and also over southern Bolivia, Paraguay, and northern Argentina. In 1983, the SACZ is somewhat defined over the South Atlantic Ocean, but similar areas of excess precipitation over the subtropical plains continue to be present in all the domains. The differences, 1985-1983, show a remarkable similarity between the domains and clearly demonstrate the control of the GCM driving fields on the simulations.

Table 4. As in Table 1 but for the South Atlantic region: $35^{\circ}-20^{\circ} \mathrm{W}, 40^{\circ}-18^{\circ} \mathrm{S}$

\begin{tabular}{|c|c|c|c|c|c|c|}
\hline \multirow[t]{2}{*}{ STAT } & \multicolumn{3}{|l|}{1983} & \multicolumn{3}{|l|}{1985} \\
\hline & GCM & D-ATL & D-PAC & GCM & D-ATL & D-PAC \\
\hline \multicolumn{7}{|l|}{ PPT } \\
\hline SCORR & 0.77 & 0.65 & 0.64 & 0.86 & -0.18 & -0.22 \\
\hline BIAS & 0.49 & 0.37 & 0.22 & -1.21 & -1.16 & -1.19 \\
\hline RMSE & 1.93 & 1.62 & 1.60 & 1.72 & 2.86 & 2.92 \\
\hline \multicolumn{7}{|l|}{ SLP } \\
\hline SCORR & 0.86 & 0.84 & 0.83 & 0.83 & 0.65 & 0.65 \\
\hline BIAS & 1.08 & 1.19 & 1.44 & 2.66 & 5.25 & 5.22 \\
\hline RMSE & 0.86 & 0.84 & 0.83 & 2.82 & 5.58 & 5.56 \\
\hline
\end{tabular}




\section{S. A. Rauscher et al.}

Table 3 lists the performance statistics for the seasonally averaged (JFM) precipitation and sea level pressure for 1983 and 1985 over the SACZ region, here defined as $55^{\circ}-30^{\circ} \mathrm{W}: 30^{\circ}-15^{\circ} \mathrm{S}$. When considering both years, the control domain (D-CTRL) appears to perform slightly better than the sensitivity domains over the SACZ region. In 1985, the spatial pattern correlations for precipitation are weakly positive for the ECHAM GCM and weakly negative for the regional model domains. There is a negative precipitation bias in the GCM and in all the regional model domains. The RMSE is larger for every regional model domain than it is for the ECHAM GCM, and there appear to be increasing errors with increasing domain size. These errors are indicative of the reduced precipitation over the SACZ in the regional model simulations.

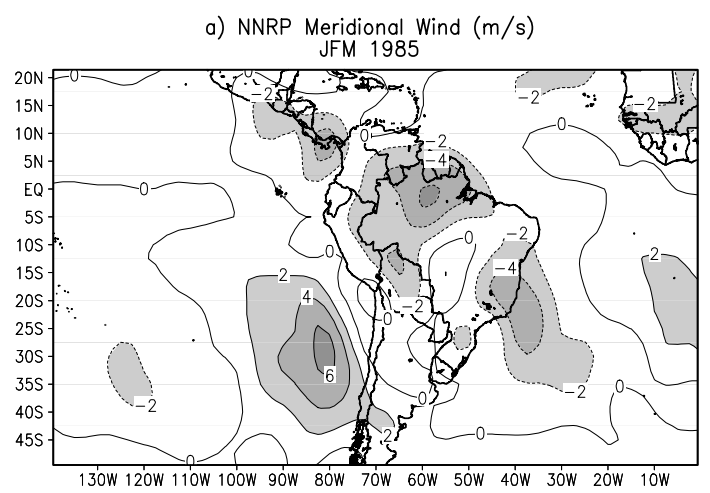

b) RegCM3_ECHAM D-PAC Meridional Wind $(\mathrm{m} / \mathrm{s})$

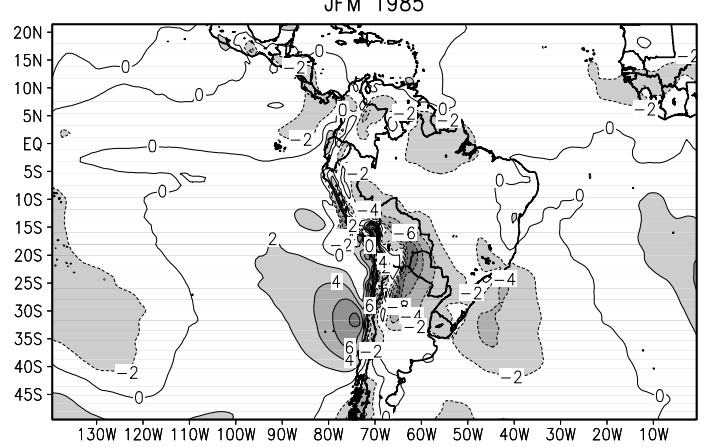

c) ECHAM Meridional Wind $(\mathrm{m} / \mathrm{s})$

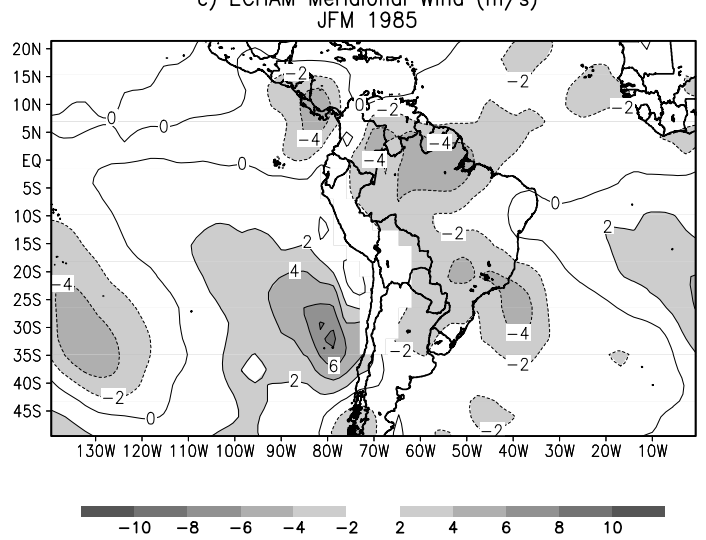

c) NNRP VIMT $(\mathrm{kg} / \mathrm{m} / \mathrm{s})$

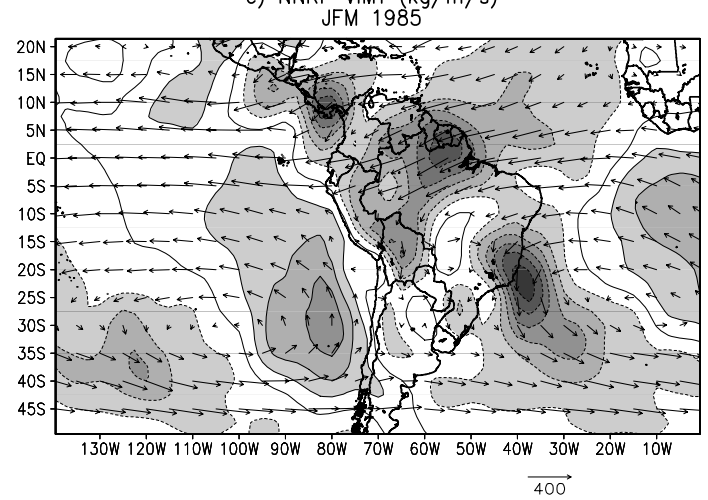

d) RegCM3_ECHAM D-PAC VIMT $(\mathrm{kg} / \mathrm{m} / \mathrm{s})$

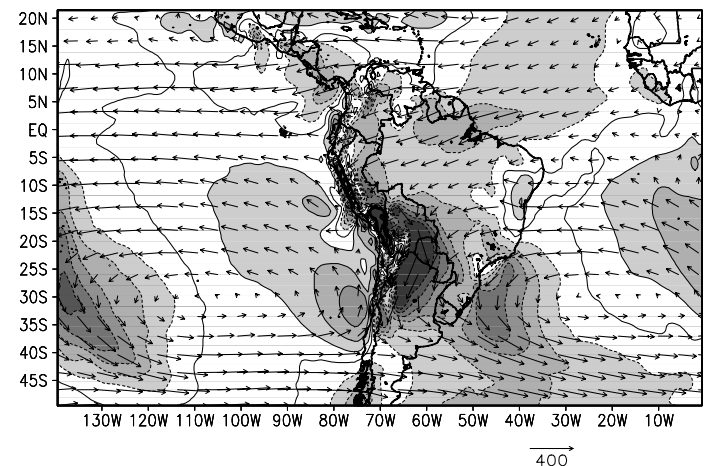

f) $\operatorname{ECHAM~VIMT~}(\mathrm{kg} / \mathrm{m} / \mathrm{s})$

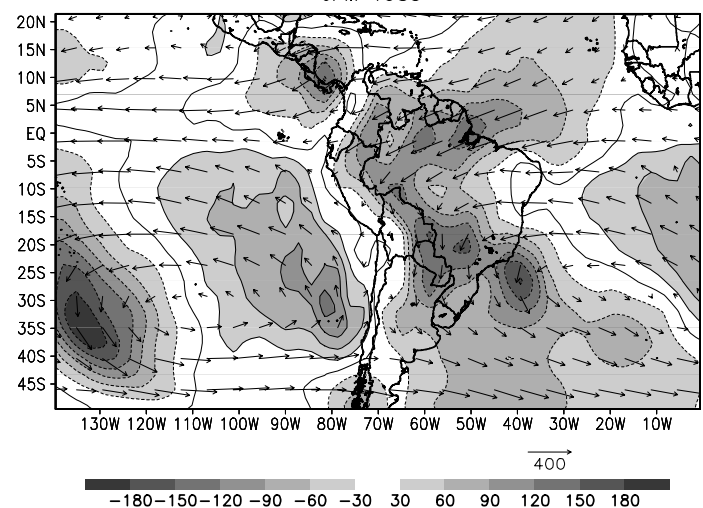

Fig. 9. Contours of January-March 1985 average $850 \mathrm{hPa}$ meridional wind for (a) NNRP, (b) ECHAM-driven RegCM3, and (c) ECHAM GCM and January-March 1985 average vertically integrated moisture $\left(\mathrm{kg} \mathrm{m}^{-1} \mathrm{~s}^{-1}\right)$ transport vectors and meridional component for (d) NNRP, (e) ECHAM-driven RegCM3, and (f) ECHAM GCM. Positive contours are solid, and negative contours are dashed 
This lower precipitation over the SACZ region in 1985 is likely associated with the positive errors in sea level pressure over the SACZ and South Atlantic regions $\left(35^{\circ}-20^{\circ} \mathrm{W}: 40^{\circ}-\right.$ $18^{\circ} \mathrm{S}$ ), listed in Tables 3 and 4 . The regional model SLP biases are greater than the GCM bias by 1 to $2 \mathrm{hPa}$. The large positive SLP biases appear to be the result of a strengthened South Atlantic subtropical high that is shifted southward of its observed position, originating in the GCM and amplified by the regional model. While the Amazon provides moisture for the SACZ over land areas, over the ocean the SACZ requires low level meridional moisture flux convergence along the southwestern periphery of the South Atlantic subtropical high (Kodama, 1993). Maps of the meridional component of the $850 \mathrm{hPa}$ wind and vertically integrated moisture transport for 1985 (Fig. 9) show that the v-wind maximum in the low level jet region is stronger in the regional model than in the observations and the ECHAM GCM and is shifted southward. The meridional component of the wind on the western side of the South Atlantic subtropical high is shifted southward as well. Therefore, the necessary moisture supply for the oceanic SACZ is effectively displaced southward, causing the regional model to incorrectly simulate the spatial distribution of precipitation over subtropical South America and the South Atlantic.

In 1983, the regional model errors over the SACZ and South Atlantic regions are generally smaller than those observed for 1985. For precipitation, the spatial pattern correlations between the regional model simulations and the observations are positive but lower than the GCM correlation. Over the SACZ region, most of the domains show a negative bias in precipitation. The sea level pressure field shows a positive bias around $1 \mathrm{hPa}$ over the SACZ and the South Atlantic in contrast to the negative bias in sea level pressure for the GCM. Although there is the same intensification of the northerly winds in the LLJ region in 1983 as in 1985 , the meridional component of the winds is located in a similar place and of a similar magnitude to the NNRP (not shown). This helps to account for the better performance of the regional model in 1983 compared to 1985.

Overall, the simulation of the SACZ in both the regional model and the global model may be problematic due to the thermodynamic cou- pling between the atmosphere and the ocean in this region. While SACZ variability may be remotely influenced by ENSO and its effect on the upper level circulation in the region (Robertson and Mechoso, 2000; Barreiro et al., 2002), local Atlantic SST variability also appears to play a role. In a series of coupled GCM experiments, Chavez and Nobre (2004) showed that the SACZ is strengthened and moved northward by positive SST anomalies and weakened by negative SST anomalies in the South Atlantic. However, the cloudiness present in an active SACZ reduces the amount of downward shortwave radiation, thereby cooling SSTs underneath the SACZ, as observed by Robertson and Mechoso (2000). The lack of this coupling may limit the models' ability to simulate precipitation in the SACZ region, as evidenced by an evaluation of the CPTEC/COLA atmospheric GCM (Marengo et al., 2003) in which the authors noted that the model had difficulty reproducing observed rainfall in tropical and sub-tropical convergence zones such as the SACZ.

\section{Conclusions}

The intention of this research was to evaluate the performance of the new version of the regional climate model, RegCM3, and to provide both qualitative and quantitative rationale for selecting a regional model domain to be employed for historical baseline simulations as the basis for an experimental nested prediction system. Two test simulations performed for JFM 1983 (El Niño) and JFM 1985 (La Niña) showed that the new version of the regional model captures the primary circulation and rainfall differences between the two years over tropical and subtropical South America, although there are some simulation errors. The regional model improves the simulation of the Atlantic ITCZ compared to the driving fields, especially in the dry year, 1983. Over the Amazon, the northeasterlies are weaker than observed, leading to reduced moisture transport and precipitation over the Amazon. This problem occurs in both the reanalysis-driven and GCM-driven RegCM3 and was also observed by SR03. Over subtropical South America, the nested model is dually affected by errors in the GCM simulation of the South Atlantic subtropical high and their effect on the RegCM3 simula- 


\section{S. A. Rauscher et al.}

tion of the South Atlantic subtropical high and the South American LLJ.

Three domain sensitivity experiments, each of which was designed to address specific regional climate features, were performed using the ECHAM GCM as driving fields for the same two test periods. A number of useful lessons were learned from these domain experiments. The results demonstrate very clearly the dominance of the boundary forcing on the regional simulations, as the similarities between the different domains tested were striking. Objective error statistics related to primary regional climate features were compared between the GCM and the nested regional model. Using this method, DCTRL, which extends from $94^{\circ} \mathrm{W}$ to $17^{\circ} \mathrm{W}$ and $33^{\circ} \mathrm{S}$ to $22^{\circ} \mathrm{N}$, provides the best results in tests for these two seasons. However, D-ATL, which employs the full eastward extension and leaves the western boundary of the control domain at $94^{\circ} \mathrm{W}$, did improve the simulation over the ITCZ region in 1983 compared to the GCM and D-CTRL. Given the fairly high quality of the ECHAM GCM simulations, it is not surprising that a small domain that limits the internal regional model freedom performed the best. These tests were intended to provide guidance for domain choice. In order to yield deterministic results on the best domain, multiple seasons and multiple ensemble members would be needed. Recognizing these limitations, a simple method has been provided for discussion, and the authors intend that this method will be improved upon.

\section{Acknowledgments}

Comments from two anonymous reviewers and Dr. Filippo Giorgi greatly helped to improve the manuscript. The authors are grateful to Dr. Filippo Giorgi, developer of RegCM. Dr. Jeremy Pal provided helpful advice and technical assistance in running RegCM3. Dr. Xunqiang Bi also gave guidance with the model pre- and post-processing. Ms. Huilan Li helped to develop the interface between ECHAM and RegCM3. The authors would also like to thank the Max-Planck Institute for Meteorology (Hamburg, Germany) for making ECHAM-4.5 available to the International Research Institute for Climate Prediction (IRI). Funding and resources were provided by the National Oceanic and Atmospheric Administration (NOAA) Pan-American Climate Studies (PACS) grant \#NA16GP2029 and the IRI. The IRI represents a cooperative agreement between the U.S. NOAA Office of Global Programs and Columbia University.

\section{References}

Anthes RA, Hsie EY, Kuo YH (1987) Description of the Penn State/NCAR Mesoscale Model Version 4 MM4 NCAR Tech Note, NCAR/TN-282 + STR, 66 pp [Available from the National Center for Atmospheric Research, P.O. Box 3000, Boulder, CO 80307]

Arakawa A, Schubert WH (1974) Interaction of a cumulus cloud ensemble with the large scale environment, Part I. J Atmos Sci 31: 674-701

Barreiro M, Chang P, Saravanan R (2002) Variability of the South Atlantic convergence zone simulated by an atmospheric general circulation model. J Climate 15: 745-763

Berbery EH, Barros VR (2002) The hydrologic cycle of the La Plata Basin in South America. J Hydrometeorology 3(6): 630-645

Chaves RR, Nobre P (2004) Interactions between sea surface temperature over the South Atlantic Ocean and the South Atlantic convergence zone. Geophys Res Lett 31: L03204, doi: 10.1029/2003GL018647

Chiang JHC, Kushnir J, Giannini A (2002) Deconstructing the Atlantic intertropical convergence zone variability: influence of the local cross-equatorial sea surface temperature gradient and remote forcing from the eastern equatorial Pacific. J Geophys Res 107: doi: 10.1029/ 2000JD00307

Chou SC, Tanajura CAS, Xue Y, Nobre CA (2002) Validation of the coupled Eta/SSiB model over South America. J Geophys Res 107(D20): 8088, doi: 10.1029/ 2000JD000270

Dickinson RE, Henderson-Sellers A, Kennedy PJ (1993) Biosphere-Atmosphere Transfer Scheme, BATS: version $1 \mathrm{E}$ as coupled to the NCAR Community Climate Model. NCAR Technical Note No NCAR/TN-387+STR, Boulder, CO, 72 pp [Available from the National Center for Atmospheric Research, P.O. Box 3000, Boulder, CO 80307]

Druyan LM, Fulakeza M, Lonergan P (2002) Dynamic downscaling of seasonal climate predictions over Brazil. J Climate 15: 3411-3426

Enfield DB, Mayer DA (1997) Tropical Atlantic SST variability and its relation to El Niño-Southern Oscillation. J Geophys Res 102: 929-945

Fouquart Y, Bonnel B (1980) Computation of solar heating of the Earth's atmosphere: a new parameterization. Beitr Phys Atmos 53: 35-62

Grell GA (1993) Prognostic evaluation of assumptions used by cumulus parameterizations. Mon Wea Rev 121: 764-787

Hastenrath S, Heller L (1977) Dynamics of climatic hazards in Northeast Brazil. Quart J Roy Meteor Soc 103: 77-92

Herdies DL, Da Silva A, Silva Dias MAF, Ferreira RN (2002) Moisture budget of the bimodal pattern of the summer circulation over South America. J Geophys Res 107: doi: 10.1029/2001JD000997

Holtslag AAM, DrBruijn EIF, Pan H-L (1990) A high resolution air mass transformation model for short-range weather forecasting. Mon Wea Rev 118: 1561-1575 
Jones RG, Murphy JM, Noguer M (1995) Simulations of climate change over Europe using a nested regional climate model. I: Assessment of control climate, including sensitivity to location of lateral boundaries. Quart J Roy Meteor Soc 121: 1413-1449

Kalnay E et al. (1996) The NCEP/NCAR 40-year reanalysis project. Bull Amer Met Soc 77: 437-471

Kiehl JT, Bonan GB, Boville BA, Briegleb BP, Williamson DL, Rasch PJ (1996) Description of the NCAR Community Climate Model (CCM3). NCAR Technical Note NCAR TN-420+STR, 152 pp [Available from the National Center for Atmospheric Research, P.O. Box 3000, Boulder, CO 80307]

Kodama Y-M (1993) Large-scale common features of subtropical convergence zones (the Baiu frontal zone, the SPCZ, and the SACZ). Part II: conditions of the circulations for generating the STCZs. J Meteor Soc Japan 71: 581-610

Kousky VE, Kagano MT, Cavalcanti IA (1984) A review of the Southern Oscillation: oceanic-atmospheric circulation change and related rainfall anomalies. Tellus 36A: 490-504

Marengo JA, Cavalcanti IFA, Satyamurty P, Trosnikov I, Nobre CA, Bonatti H, Camargo JP, Sampaio G, Sanches MB, Manzi AO, Castro CAC, D’Almeida C, Pezzi LP, Candido L (2003) Assessment of regional seasonal rainfall predictability using the CPTEC/COLA atmospheric GCM. Climate Dynamics 21(5/6): 459-475

Misra V, Dirmeyer PA, Kirtman BP (2002a) A comparative study of two land surface schemes in regional climate integrations over South America. J Geophys Res 107(D20): 8080, doi:10.1029/2001JD001284

Misra V, Dirmeyer PA, Kirtman BP, Juang H-MH, Kanamitsu M (2002b) Regional simulation of interannual variability over South America. J Geophys Res 107(D20): 8036, doi:10.1029/2001JD900216

Misra V, Dirmeyer PA, Kirtman BP (2003) Dynamic downscaling of seasonal simulations over South America. J Climate 16: 103-117

Misra V, Kanamitsu M (2004) Anomaly nesting: A methodology to downscale seasonal climate simulations from AGCMs. J Climate 17: 3249-3262

Morcrette J-J, Smith L, Fouquart Y (1986) Pressure and temperature dependence of the absorption in longwave radiation parameterizations. Beitr Phys Atmos 59: 455-469

Nicolini M, Salio P, Katzfey JJ, McGregor JL, Saulo AC (2002) January and July regional climate simulations over South America. J Geophys Res 107: 4637, doi: 10.1029/ 2001JD000736

Nobre P, Moura AD, Sun L (2001) Dynamical downscaling of seasonal climate prediction over Nordeste Brazil with ECHAM3 and NCEP's regional spectral models at IRI. Bull Amer Meteor Soc 82: 2787-2796

Nobre P, Shukla J (1996) Variations of sea surface temperature, wind stress, and rainfall over the tropical Atlantic and South America. J Climate 9: 2464-2479

Nogués-Paegle J, Mo KC (1997) Alternating wet and dry conditions over South America during summer. J Climate 125: 279-291
Paegle J (1998) A comparative review of South American low-level jets. Meteorologica 23: 73-81

Paegle JN, Mo KC (2002) Linkages between summer rainfall variability over South America and sea surface temperature anomalies. J Climate 15: 1389-1407

Pal JS, Small EE, Eltahir EAB (2000) Simulation of regional-scale water and energy budgets: Representation of subgrid cloud and precipitation processes within RegCM. J Geophys Res 105: 29579-29594

Pal JS et al. (2006) The ICTP RegCM3 and RegCNET: Regional climate modeling for the developing world. Bull Amer Meteor Soc (in review)

Qian J-H, Seth A, Zebiak S (2003) Reinitialized versus continuous simulations for regional climate downscaling. Mon Wea Rev 131: 2857-2873

Reynolds RW, Rayner NA, Smith TA, Stokes DC, Wang W (2002) An improved in situ and satellite SST analysis for climate. J Climate 15: 1609-1625

Roads J, Chen S, Cocke S, Druyan L, Fulakeza M, LaRow T, Lonergan P, Qian J-H, Zebiak S (2003) International Research Institute/Applied Research Centers (IRI/ARCs) $\mathrm{ARCs})$ regional model intercomparison over South America. J Geophys Res 108(D14): 4425, doi: 10.1029/ 2002JD003201

Robertson AW, Mechoso CR (2000) Interannual and interdecadal variability of the South Atlantic convergence zone. Mon Wea Rev 128: 2947-2957

Roeckner E, Arpe K, Bengtsson L, Christoph M, Claussen M, Dumenil L, Esch M, Giorgetta M, Schlese U, Schulzweida U (1996) The atmospheric general circulation model ECHAM-4: Model description and simulation of presentday climate. Tech Rep 218, Max-Planck Institute for Meteorology, Hamburg, Germany, 90 pp

Rojas M, Seth A (2003) Simulation and sensitivity in a nested modeling system for South America. Part II: GCM Boundary Forcing. J Climate 16: 2454-2471

Ropelewski CF, Halpert MS (1987) Global and regional scale precipitation patterns associated with the El Niño/Southern Oscillation. Mon Wea Rev 115: 1606-1626

Schwerdtfeger W (1976) Climates of Central and South America, World Survey of Climatology, Vol. 12. New York: Elsevier Science, 522 pp

Seluchi MM, Marengo JA (2000) Tropical-midlatitude exchange of air masses during summer and winter in South America: Climatic aspects and examples of intense events. Int J Climatol 20: 1167-1190

Seth A, Giorgi F (1998) The effects of domain choice on summer precipitation: Simulation and sensitivity in a regional climate model. J Climate 10: 2698-2712

Seth A, Rojas M (2003) Simulation and sensitivity in a nested modeling system for South America. Part I: Reanalyses Boundary Forcing. J Climate 1615: 2437-2453

Simmons AJ, Burridge DM, Jarraud M, Girard C, Wergen W (1989) The ECMWF medium-range prediction models: Development of the numerical formulations and the impact of increased resolution. Meteorol Atmos Phys 40: $28-60$

Sun L, Moncunill DF, Li H, Moura AD, Filho FAS (2005) Climate downscaling over Nordeste, Brazil, using the NCEP RSM97. J Climate 18: 551-567 
Tiedtke M (1989) A comprehensive mass flux scheme for cumulus parameterization on large scale models. Mon Wea Rev 117: 1779-1800

Uvo CB, Repelli CA, Zebiak SE, Kushnir Y (1998) The relationships between tropical Pacific and Atlantic SST and Northeast Brazil monthly precipitation. J Climate 11: $551-562$

Vannitsem S, Chomé F (2005) One-way nested regional climate simulations and domain size. J Climate 18: 229-233

Virji H (1981) A preliminary study of summertime tropospheric circulation patterns over South America estimated from cloud winds. Mon Wea Rev 109: 599-610

Xie P, Arkin PA (1996) Analyses of global monthly precipitation using gauge observations, satellite esti- mates, and numerical model predictions. J Climate 9: $840-858$

Zeng X, Zhao M, Dickinson RE (1998) Intercomparison of bulk aerodynamic algorithms for the computation of sea surface fluxes using TOGA COARE and TAO data. J Climate 11: 2628-2644

Authors' addresses: Sara A. Rauscher (e-mail: srausche@ ictp.it), Physics of Weather and Climate Group, The Abdus Salam International Centre for Theoretical Physics, Strada Costiera 11, 34014 Trieste, Italy; Anji Seth, Department of Geography, University of Connecticut, 215 Glenbrook Road, Unit 4148, Storrs, CT 06296, USA; Jian-Hua Qian, Suzana J. Camargo, International Research Institute for Climate Prediction, Columbia University, LDEO, Monell Building, Palisades, Rt 9W, NY 10964, USA. 